\title{
Pharmacokinetics of pancreatic polypeptide in man
}

\author{
T. E. ADRIAN, G. R. GREENBERG, H. S. BESTERMAN, AND S. R. BLOOM \\ From the Department of Medicine, Royal Postgraduate Medical School, Hammersmith Hospital, \\ London
}

SUMMARY Pure bovine pancreatic polypeptide (PP) was infused into 23 healthy subjects at doses of 1,3 , and $5 \mathrm{pmol} / \mathrm{kg} / \mathrm{min}$ over 60 minutes and plasma PP was measured by radioimmunoassay. During the infusions mean plasma levels of $203 \pm 34,575 \pm 73$, and $930 \pm 48 \mathrm{pmol} / \mathrm{l}$ respectively were achieved. Mean disappearance half time on stopping the infusion was $6.9 \pm 0.3$ min (mean \pm SEM). The metabolic clearance rate was $5.1 \pm 0.2 \mathrm{ml} / \mathrm{kg} / \mathrm{min}$ (mean \pm SEM) and the apparent volume of distribution was calculated to be $51 \pm 3 \mathrm{ml} / \mathrm{kg}$ (mean $\pm \mathrm{SEM}$ ). This study provides for the first time pharmacokinetic data for PP in man.

Pancreatic polypeptide (PP) is a recently discovered hormonal 36 amino acid peptide localised in an endocrine cell of the mammalian and avian pancreas (Kimmel et al., 1968; Lin and Chance, 1972). PP circulates in plasma and levels rise substantially on the ingestion of a meal and remain raised for several hours (Adrian et al., 1976; Floyd et al., 1976; Schwartz et al., 1976). This release of PP is elicited via an 'entero-PP axis' which appears to involve the vagus and circulating gastrointestinal hormones (Schwartz et al., 1976; Adrian et al., 1977).

PP has a broad spectrum of biological actions on the mammalian gastrointestinal tract. When infused into dogs bovine pancreatic polypeptide (BPP) caused a marked inhibition of pancreatic and biliary secretion (Lin and Chance, 1972; Lin et al., 1977). These effects have also been observed in man after low dose BPP infusions (Adrian et al., 1978b; Greenberg et al., 1978). PP is found in high concentrations in the mammalian pancreas and thus the bovine peptide is a by-product of commercial insulin preparation and is readily available in pure form for use in physiological investigations.

\section{Methods}

SUBJECTS

Twenty-three volunteers aged $37 \cdot 5 \pm 2 \cdot 3$ years (mean $\pm \mathrm{SEM}$ ) and weighing $71 \cdot 3 \pm 2 \cdot 2 \mathrm{~kg}$ (mean \pm SEM) with no evidence of gastrointestinal or renal disease were studied. All subjects gave informed consent. After an overnight fast an anticubital vein was catheterised and $0.15 \mathrm{M}$ saline with human serum albumin $(200 \mu \mathrm{mol} / \mathrm{l})$ was infused from a

Received for publication 4 May 1978 syringe ram pump for a basal period of 30 minutes. BPP was then added to the infusion at nominal doses of $1(n=6), 3(n=9)$, and $5(n=8) \mathrm{pmol} /$ $\mathrm{kg} / \mathrm{min}$.

Blood samples were collected in chilled tubes with 10 units heparin and $400 \mathrm{KIU}$ aprotinin (Trasylol) per $\mathrm{ml}$, centrifuged, and the plasma frozen within 15 minutes of sampling. At the end of each infusion a sample of infusate was collected from the venous end of the catheter for PP measurement.

During each PP infusion pulse rate, blood pressure, body temperature, and ECG were monitored and blood was taken for routine haematological and biochemical tests (blood glucose, blood urea, electrolytes, liver function tests, calcium, and phosphate). No objective or subjective side-effects were noted and all screening measurements remained unchanged.

Plasma and infusate concentrations of PP were measured using a radioimmunoassay described in detail elsewhere (Adrian et al., 1976). The antibody used for these studies was raised to pure bovine PP and had a final dilution in the assay of 1 in 1600000 . The system was further modified in that bovine PP was used to prepare the radioactive label in exactly the same manner as has previously been described for human PP (Adrian et al., 1976). Pure bovine PP standards were used in the assay. No cross-reactivity was detected with up to $500 \mathrm{nmol}$ each of insulin, glucagon, gastrin, gastric inhibitory peptide, secretin, vasoactive intestinal peptide, cholecystokinin, or motilin. Changes of $5 \mathrm{pmol} \mathrm{PP} / 1$ plasma can be detected with $95 \%$ confidence.

Calculations of pharmacokinetic data were based on 
the plateau principle described by Goldstein et al. (1974). To determine the half-time of decay $\left(t \frac{1}{2}\right)$ of PP each subject's mean basal level was subtracted from all subsequent values. The post-infusion values were normalised by expressing them as a percentage of the previous steady state level. These values were then converted to their natural logarithms and were plotted against time. The $t \frac{1}{2}$ value for each infusion was derived from the resulting straight line plot. In addition the mean of the normalised data for all 23 infusions for each time period was calculated. These values were converted to natural logarithms and linear regression analysis was performed. The metabolic clearance rate (MCR) was calculated by dividing the infusion rate (in $\mathrm{pmol} / \mathrm{kg} / \mathrm{min}$ ) by the steady state increment in plasma PP (in $\mathrm{pmol} / \mathrm{ml}$ ). The apparent space of distribution (DS) was calculated from the formula:

$$
\text { DS }(\mathrm{ml} / \mathrm{kg})=\mathrm{MCR} \times \mathrm{t} \frac{1}{2} \times 1.44
$$

\section{Results}

The mean PP dose measured by radioimmunoassay and the half-life, metabolic clearance rate, and distribution space calculated for each of the three infusion doses can be seen in the Table. For all the 23 infusions the mean half-life was $6.9 \pm 0.3$ (mean \pm SEM) minutes, MCR $5.1 \pm 0.2 \mathrm{ml} / \mathrm{kg} / \mathrm{min}$, and apparent space of distribution $51 \pm 3 \mathrm{ml}$.

The mean plasma levels of PP in nine subjects during infusion of the middle PP infusion dose $(2.84 \pm 0.18 \mathrm{pmol} / \mathrm{kg} / \mathrm{min})$ is shown in Fig. 1. The mean basal and plateau PP concentrations for all three doses can be seen in the Table. The steady state increments of plasma PP reflect the grading of the three infusion doses $(1: 2 \cdot 8: 4 \cdot 6)$ as would be
Table Basal and plateau plasma PP concentrations, half-time for decay $\left(t \frac{1}{2}\right)$, metabolic clearance rate $(M C R)$, and apparent distribution space $(D S)$ for $B P P$ infusions in 23 subjects at three dose levels

\begin{tabular}{|c|c|c|c|}
\hline PP dose $(\mathrm{pmol} / \mathrm{kg} / \mathrm{min})$ & $\begin{array}{l}0.98 \pm 0.13 \\
(n=6)\end{array}$ & $\begin{array}{l}2.84 \pm 0.18 \\
(n=9)\end{array}$ & $\begin{array}{l}4.58 \pm 0.34 \\
(n=8)\end{array}$ \\
\hline $\begin{array}{l}\text { Basal plasma PP } \\
\text { Concn (pmol/l) }\end{array}$ & $20 \pm 5$ & $18 \pm 4$ & $22 \pm 3$ \\
\hline $\begin{array}{l}\text { Plateau plasma PP } \\
\text { Concn (pmol/l) }\end{array}$ & $203 \pm 34$ & $575 \pm 73$ & $930 \pm 48$ \\
\hline $\begin{array}{l}\mathrm{t} \frac{1}{2}(\mathrm{~min}) \\
\operatorname{MCR}(\mathrm{ml} / \mathrm{kg} / \mathrm{min})\end{array}$ & $\begin{array}{l}6.9 \pm 0.5 \\
5 \cdot 2 \pm 0.4\end{array}$ & $\begin{array}{l}6.9 \pm 0.6 \\
5.0 \pm 0.4\end{array}$ & $\begin{array}{l}7 \cdot 0 \pm 0 \cdot 6 \\
5 \cdot 1 \pm 0 \cdot 4\end{array}$ \\
\hline $\mathrm{DS}(\mathrm{ml})$ & $50 \pm 2$ & $50 \pm 6$ & $53 \pm 5$ \\
\hline
\end{tabular}

expected if endogenous PP secretion were not suppressed during the administration of exogenous PP. This finding validates the subtraction of baseline levels when calculating the pharmacokinetic data.

Figure 2 shows the normalised data of the postinfusion period plotted semi-logarithmically versus time. A good fit to the calculated linear regression line was noted with a correlation coefficient of 0.999.

\section{Discussion}

Our studies show that exogenously administercd BPP is rapidly cleared from the circulation in man. The course of disappearance follows first order kinetics with a half-life of seven minutes.

The apparent distribution space suggests that PP was distributed mainly in the plasma volume. A similar small volume of distribution would be expected for a substance bound to a carrier molecule in plasma. This is unlikely, however, as results of gel chromatograms of plasma from normal subjects show only one major peak of PP immunoreactivity eluting in the same position as pure PP (unpublished observations).

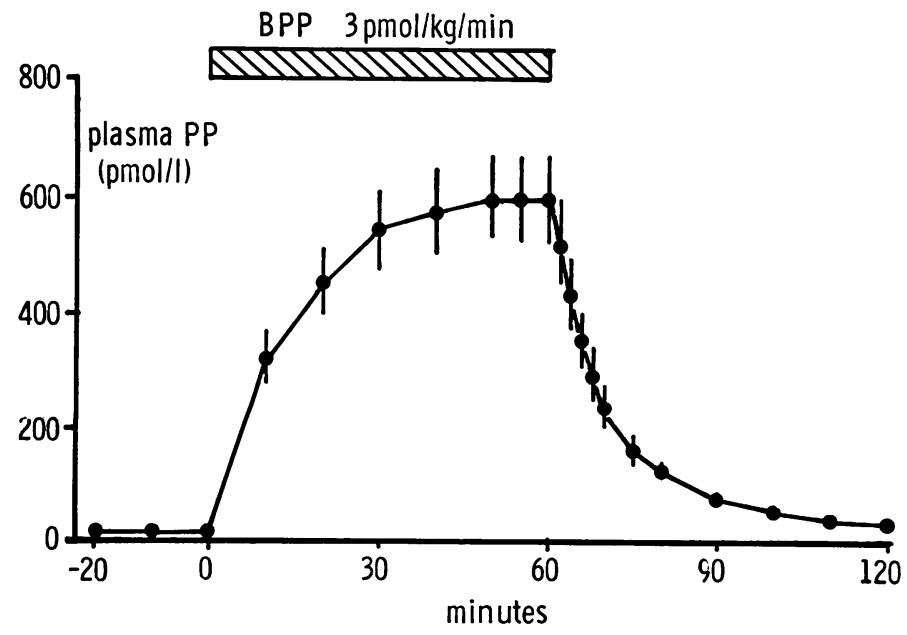

Fig. 1 Plasma PP concentrations during a $3 \mathrm{pmol} / \mathrm{kg} / \mathrm{min}$ pure bovine pancreatic polypeptide infusion over 60 minutes in nine healthy subjects (SEM marked with bar). 


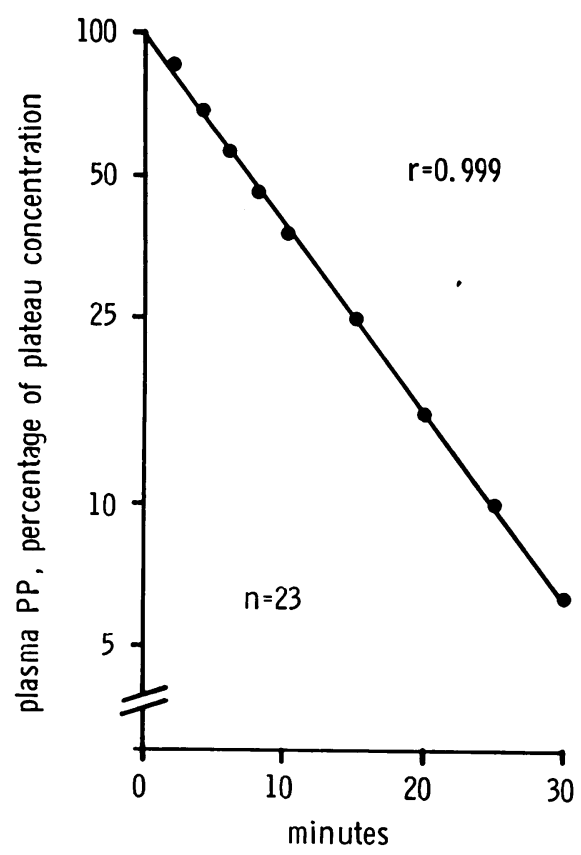

Fig. 2 Plasma PP decay after discontinuing intravenous infusion plotted as mean percentage of steady state infusion increment. Linear decay suggests first order kinetics.

The amino acid sequence of BPP is very similar to that of the human peptide, the only differences being in position 6 in which glycine replaces valine and in position 23 where glutamic acid replaces aspartic acid (Chance and Jones, 1974). Because of this similarity in structure, differences in pharmacokinetics between BPP are not anticipated; however, this can be determined only when sufficient pure human peptide is available. Certainly the decay rate of endogenous PP following somatostatin suppression gives a roughly similar half-life (approximately eight minutes) to that observed here. Plasma PP levels rise substantially on the ingestion of food (Adrian et al., 1976; Floyd et al., 1976; Schwartz et al., 1976), particularly protein and fat (Adrian $e t$ al., 1978a), and levels of approximately $200 \mathrm{pmol} / 1$ are seen after the ingestion of a small mixed breakfast in young adults (Adrian et al., 1976). After a larger meal PP levels rise to a peak of approximately $350 \mathrm{pmol} / \mathrm{l}$ in healthy young subjects (Adrian et al., 1977). Thus the plasma levels achieved with our PP infusions at the lower dose are within the physio- logical range and the higher doses reflect rises two to three times greater than those observed after a normal lunch. At a dose of $3.3 \mathrm{pmol} / \mathrm{kg} / \mathrm{min}$ BPP causes a marked inhibition of duodenal juice protein, trypsin, and bilirubin content during submaximal secretin stimulation (Adrian et al., 1978b) and a similar effect was noted on basal pancreatic and biliary function (Greenberg et al., 1978). At the present time the precise physiological role of PP is unclear, but the high plasma concentrations which can occur and potent gastrointestinal effects emphasise the importance of further studies.

\section{References}

Adrian, T. E., Besterman, H. S., Bryant, M. G., and Bloom, S. R. (1978a). Physiology of PP II. In Gut Hormones. Edited by S. R. Bloom. Churchill Livingstone: Edinburgh. Adrian, T. E., Besterman, H. S., Mallinson, C. N., Greenberg, G. R., and Bloom, S. R. (1978b). Inhibition of secretin stimulated pancreatic secretion by pancreatic polypeptide. Gut. (In press.)

Adrian, T. E., Bloom, S. R., Besterman, H. S., Barnes, A. J., Cooke, T. J. C., Russell, R. C. G., and Faber, R. G. (1977). Mechanism of pancreatic polypeptide release in man. Lancet, 1, 161-163.

Adrian, T. E., Bloom, S. R., Bryant, M. G., Polak, J. M., Heitz, P., and Barnes, A. J. (1976). Distribution and release of human pancreatic polypeptide. Gut, 17, 940-944.

Chance, R. E., and Jones, W. F. (1974). Polypeptides from bovine, ovine, human and porcine pancreas. United States Patent Office $X-3097 A, 22,3,824,063$.

Floyd, J. C., Jr., Fajans, S. S., and Pek, S. (1976). Regulation in healthy subjects of the secretion of human pancreatic polypeptide, a newly recognised pancreatic islet polypeptide. Transactions of the Association of American Physicians, 89, 146-158.

Goldstein, A., Aronow, L., and Kalman, S. M. (1974). Principles of Drug Action; the Basis of Pharmacology, pp. 311-322. Wiley: New York.

Greenberg, G. R., McCloy, R. F., Adrian, T. E., Chadwick, V. S., Baron, J. H., and Bloom, S. R. (1978). Effect of bovine pancreatic polypeptide on basal pancreatic and biliary outputs in man. American Journal of Digestive Diseases. (In press.)

Kimmel, J. R., Pollock, H. G., and Hazelwood, R. L. (1968). Isolation and characterization of chicken insulin. Endocrinology, 83, 1323-1330.

Lin, T. M., and Chance, R. E. (1972). Spectrum gastrointestinal actions of a new bovine pancreas polypeptide (BPP) (Abstract). Gastroenterology, 62, 852.

Lin, T. M., Evans, D. C., Chance, R. E., and Spray, G. F. (1977). Bovine pancreatic polypeptide: action on gastric and pancreatic secretion in dogs. American Journal of Physiology, 232E, 311-E315.

Schwartz, T. W., Stadil, F., Chance, R. E., Rehfeld, J. F., Larson, L. I., and Moon, N. (1976). Pancreatic-polypeptide response to food in duodenal-ulcer patients before and after vagotomy. Lancet, 1, 1102-1105. 